\title{
ЗАКОНОМЕРНОСТИ ВЛИЯНИЯ МОТИВАЦИОННОЙ СФЕРЫ КОМАНДИРОВ МЛАДШЕГО ЗВЕНА НА НАПРАВЛЕННОСТЬ МЕЖЛИЧНОСТНЫХ ОТНОШЕНИЙ
}

\author{
Юлия Станиславовна Мигунова \\ капитан внутренней службы, преподаватель \\ Ивановская пожарно-спасательная академия ГПС МЧС России \\ 2. Иваново, Россия \\ E-mail: sttassiya@rambler.ru
}

Статья посвящена проблеме построения взаимоотношений между командирами младшего звена и курсантами учебных заведений ГПС МЧС России в прочессе учебно-служебной деятельности. Наше исследование основано на анализе влияния мотивационной сферы командиров на направленность интерперсональных отношений в процессе их взаимодействия с подчиненными курсантами.

Проблемным для нас представляется вопрос сочиально-психологического отбора претендентов на сержантские должности в учебных заведениях экстремального профиля. Исходя из результатов исследования, важной представляется алгоритмизация отбора младших командиров с учетом их тенденций во взаимоотношениях с окружающими.

В данной части исследования, которая освещена в статье, мы рассматриваем особенности мотивации младших командиров, среди которых: выраженность мотивации достижения успеха, склонность к манипулированию другими людьми, преобладающая направленность в учебно-служебной деятельности. Также анализируем реальную и идеальную структуру интерперсональной направленности сержантского состава с точки зрения самих младших командиров и их подчиненных курсантов.

Исследование показало, что деловая направленность, которая должна выражаться в стремлении управлять группой в процессе учебно-служебной деятельности и добиваться ее наилучшей продуктивности, у большинства младших командиров не сформирована; младшие командиры не всегда самостоятельно могут оценить свою способность к взаимодействию с коллективом; важную роль в структуре интерперсональной направленности командиров младшего звена играет уровень выраженности подозрительности.

Результаты исследования планируется использовать при разработке программы по предварительному отбору младших командиров уже на первом 
году обучения; при разработке программы, направленной на оптимизацию отношений младших командиров с командованием курса и подчиненными курсантами.

Ключевые слова: взаимоотношения, мотивачия, интерперсональные отношения, макиавеллизм, мотивачия достижения, оценка, самооценка, управленческий потенциал, социально-психологический отбор, система подготовки.

Для цитирования: Мигунова Ю. С. Закономерности влияния мотивационной сферы командиров младшего звена на направленность межличностных отношений // Российский психологический журнал. - 2016. - Т. 13. - № 3. - С. 312-327.

\title{
MECHANISMS OF THE INFLUENCE OF THE MOTIVATIONAL SPHERE OF JUNIOR COMMANDERS ON THE ORIENTATION OF INTERPERSONAL RELATIONSHIPS
}

\author{
Iuliia Stanislavovna Migunova \\ Captain of Internal Service, Lecturer \\ Academy of State Fire Service EMERCOM Russia \\ Ivanovo, Russia \\ E-mail: sttassiya@rambler.ru
}

The article deals with the relationships between junior commanders and cadets of educational institutions of Russian State Fire Service of the Ministry of Emergency Situations in the process of training and service activities. The present study analyzes the influence of the motivational sphere of commanders on the orientation of interpersonal relationships when interacting with subordinate cadets.

An important problem was socio-psychological selection of candidates for sergeant's positions in schools of an extreme profile. Findings of the study are of direct practical relevance for the algorithmization of selection of junior commanders with regard to their relationships with others.

The paper covers a part of the study where the authors consider the following features of the motivation of junior commanders: (a) prominence of achievement motivation, (b) tendency to manipulate other people, and (c) prevailing orientation in teaching and service activities. The authors also analyze the real and the ideal structure of the interpersonal orientation of sergeants from the point of view of junior commanders and their subordinates.

The results of the study showed that business orientation, expressed in the desire to control the group in training and service activities and to achieve its best efficiency, was 
unformed in the majority of junior commanders. Junior officers were not always able to assess their ability to interact with the team independently. The level of suspiciousness plays an important role in interpersonal orientation of junior commanders.

The results of the study are of direct practical relevance for the development of (a) the program for pre-selection of junior commanders even at the first year of training and (b) the program for the improvement of relationships between junior commanders, command, and subordinated cadets.

Keywords: relationships, motivation, interpersonal relationships, Machiavellianism, achievement motivation, appraisal, self-appraisal, managerial potentional, sociopsychological selection, training system.

For citation: Migunova lu. S. Mechanisms of the Influence of the Motivational Sphere of Junior Commanders on the Orientation of Interpersonal Relationships. Russian Psychological Journal, 2016, V. 13, no. 3, pp. 312-327.

\section{Введение}

Социально-психологические особенности младших командиров играют важную роль в деятельности учебной группы как структурной единицы учебного коллектива. Они предопределяют настроение, направленность и основные ценности группы (учеба, служба, межличностные отношения, власть, самоутверждение и т. д.). В зависимости от своих личностных особенностей младшие командиры выстраивают особый вид межличностных отношений, который отличается спецификой интерперсональных направленностей.

Многие курсанты, поступив в образовательные учреждения МЧС России, стремятся попасть в ряды сержантского состава, чтобы иметь возможность выделиться из общей группы новобранцев, реализоваться как командир, совершенствовать свои управленческие качества. Но имеются и отрицательные мотивы становления на должности младших командиров, проявления которых необходимо контролировать. Отрицательным мотивом может явиться желание самоутвердиться за счет «приближенного» положения к командованию курса и за счет возможности чувствовать себя «выше» своих однокурсников.

Деятельность человека всегда обусловлена реально существующими потребностями: люди стремятся либо чего-то достичь, либо чего-то избежать [4].

В общем виде под мотивацией человека к деятельности понимается совокупность движущих сил, побуждающих человека к осуществлению определенных действий. Стимулы могут находиться как внутри человека (внутренняя мотивация), так и воздействовать на него с помощью внешней среды (внешняя мотивация). При этом человек может осознавать или не осознавать истинные мотивы своего поведения, присваивая стремления и желания других людей [2]. 
Деятельность командира представляет собой сложный управленческий процесс, качество которого зависит от наличия необходимых знаний, опыта и профессионально важных личностных характеристик. Поступив в высшее учебное заведение, младшие командиры в своей управленческой деятельности могут опираться лишь на свои личностные особенности. Если алгоритм профессионального психологического отбора и назначения на офицерские должности отработан успешно и работает уже многие годы, то процедура выбора и назначения на сержантские должности из вновь поступивших курсантов четко не определена. Из-за данной ситуации, на первом году обучения в учебных коллективах МЧС России присутствует постоянная ротация младших командиров. При отсутствии разработанной схемы назначения курсантов на сержантские должности происходит их «пробное» поочередное назначение на «испытательные сроки» без присвоения сержантских званий. То есть, в структуре профессионального отбора в учебных учреждениях ГПС МЧС России на данный момент нет научно обоснованного подхода к назначению курсантов на должности младших командиров, учитывающего их социально-психологические особенности. Постоянная смена командиров учебных групп обучения препятствует реализации полноценного учебно-воспитательного процесса на первом году обучения.

Хороший командир младшего звена должен «начинаться» с качественного социально-психологического отбора, который позволит определить выраженность тех психологических качеств и направленностей, которые лежат в основе управленческого потенциала кандидата [11, 14].

В данном исследовании мы рассматриваем взаимосвязь между мотивационной сферой личности младших командиров и направленностью их межличностных отношений с подчиненными курсантами.

\section{Методика}

Материалы эмпирического исследования были получены с использованием следующих психодиагностических методик:

1) Мак-шкала В. В. Знакова;

2) тест мотивации достижения А. Мехрабиана;

3) опросник Т. Лири для исследования межличностных отношений;

4) методика изучения направленности личности (методика В. Смекала и М. Кучера).

Материалы исследования обрабатывались с помощью методов математической статистики с использованием компьютерных программ Microsoft Excel, SPSS14.0. В исследовании был использован коэффициент корреляции Пирсона. 
Эксперимент проводился среди курсантов и младших командиров первого, третьего и пятого годов обучения Ивановской пожарно-спасательной академии ГПС МЧС России. Общая численность выборки составила 470 человек: 105 человек-командиры отделений и заместители командиров учебных групп, и 365 человек-рядовые курсанты.

\section{Результаты и их обсуждение}

Сначала проанализируем особенности мотивационной сферы командиров младшего звена. Особое внимание обратим на выраженность мотивации достижения успеха, склонность к манипулированию другими людьми, преобладающую направленность учебно-служебной деятельности.

Таблица 1.

Средние значения шкал у командиров младшего звена по методикам мотивационной направленности

\begin{tabular}{|c|c|c|c|c|}
\hline № $n / n$ & Название методики & Шкалы & $\begin{array}{c}\text { Уровень вы- } \\
\text { раженности } \\
\text { шкалы }\end{array}$ & Интерпретация \\
\hline 1. & $\begin{array}{c}\text { Мак-шкала } \\
\text { В.В. Знакова }\end{array}$ & Макиавеллизм & 69,1 & $\begin{array}{c}\text { Средний } \\
\text { уровень } \\
\text { напряженности }\end{array}$ \\
\hline 2. & $\begin{array}{c}\text { Тест мотива- } \\
\text { ции достижения } \\
\text { А. Мехрабиана }\end{array}$ & $\begin{array}{l}\text { Мотивация } \\
\text { достижения }\end{array}$ & 139,4 & $\begin{array}{c}\text { Преобладание } \\
\text { мотива избега- } \\
\text { ния неудачи }\end{array}$ \\
\hline \multirow{3}{*}{3.} & \multirow{3}{*}{$\begin{array}{c}\text { Методика изучения } \\
\text { направленности } \\
\text { личности (мето- } \\
\text { дика В. Смекала } \\
\text { и М. Кучера) }\end{array}$} & $\begin{array}{c}\text { Направленность } \\
\text { на себя }\end{array}$ & 30,3 & \multirow{3}{*}{$\begin{array}{c}\text { Преобладает } \\
\text { направленность } \\
\text { на взаимодей- } \\
\text { ствие }\end{array}$} \\
\hline & & $\begin{array}{c}\text { Направленность } \\
\text { на взаимодей- } \\
\text { ствие }\end{array}$ & 31,6 & \\
\hline & & $\begin{array}{c}\text { Направленность } \\
\text { на задачу }\end{array}$ & 28 & \\
\hline
\end{tabular}

Охарактеризуем макиавеллизм как склонность человека к манипулированию другими людьми в межличностных взаимоотношениях, «едва уловимыми или нефизически агрессивными способами, такими, как лесть, обман, подкуп или запугивание» [20, с. 223]. В. В. Знаков отмечает, что во многих психологических исследованиях макиавеллисты характеризуются как умные, решительные, амбициозные, доминирующие, настойчивые, эгоистичные, эмоционально холодные, ригидные в коммуникативных взаимодействиях. Особенность макиавеллиста - рассмотрение другого человека как объекта воздействия, а не субъекта взаимодействия [5, 7]. Данный показатель определяет наличие тенденций к использованию манипулятивных стратегий поведения [3]. 
Мы выявили средний уровень макиавеллизма, который характерен для младших командиров. Показатель, равный $\mathrm{M}=69,1$ по шкале макиавеллизма, говорит об умеренной способности влиять на поведение людей и подчинять их поведения своим желаниям. Среднее значение макиавеллизма говорит об адекватной самооценке, тенденции к доминантности, способности отстаивать свое мнение. Однако стоит отметить такую закономерность: чем выше показатель макиавеллизма, тем менее выраженной оказывается мотивация достижения $(r=-0,332$, при $p \leq 0,01)$. Среднее значение мотивации достижения при размахе Мак-шкалы от 36 до 74 (склонность к манипулированию ниже средних значений) $\mathrm{M=148,} \mathrm{а} \mathrm{среднее} \mathrm{значение} \mathrm{мотивации} \mathrm{достижения}$ при размахе Мак-шкалы от 75 до 107 (склонность к манипулированию выше средних значений) $\mathrm{M}=135$. Данные показатели говорят о недостаточной сформированности навыков управления у младших командиров $[8,10]$.

Таким образом, средний показатель по шкале мотивации достижения у командиров младшего звена $M=139,4$, что говорит о преобладании у них мотивации стремления избегать неудачи. Командиры отделений с данным типом мотивации предпочитают не рисковать своей репутацией и выбирать те стратегии поведения, которые уже проверены или не приведут к негативным последствиям. Их самооценка уязвима к мнению референтных лиц, которыми в данный период становления являются курсовые офицеры и профессорско-преподавательский состав.

Обратим внимание на особенность направленности личности младших командиров. Назначение исследования по данному параметру-определение направленности: личностной (на себя), деловой (на задачу) и коллективистской (на взаимодействие) [1]. В данном случае у сержантского состава (таблица 1) преобладает направленность на взаимодействие $M=31,6$ в сочетании с направленностью на себя $M=30,3$. Данные результаты говорят о том, что младшие командиры в учебных коллективах МЧС России руководствуются в своей управленческой деятельности потребностью в общении, стремлением поддерживать хорошие отношения с товарищами, а также стремлением к личному первенству и мотивами собственного благополучия. То есть, здесь можно сделать вывод о недостаточной выраженности желаемой деловой направленности младших командиров, которая должна выражаться в стремлении управлять группой в процессе учебно-служебной деятельности и добиваться ее продуктивности.

Далее мы рассмотрели доминирующие направленности интерперсональных отношений личности (таблица 2). Сначала мы попросили младших командиров ответить на опросник Т. Лири [16], а затем на те же вопросы отвечали их подчиненные курсанты, оценивая качества младших командиров со своей точки зрения. 
Таблица 2.

Средние значения шкал по опроснику Т. Лири для исследования межличностных отношений у командиров младшего звена в результате самооценки и оценки подчиненными курсантами

\begin{tabular}{|c|c|c|c|c|}
\hline \multirow{2}{*}{ Noo $n / n$} & \multirow{2}{*}{$\begin{array}{c}\text { Виды направлен- } \\
\text { ностей меж- } \\
\text { личностных } \\
\text { отношений }\end{array}$} & \multicolumn{2}{|c|}{ Уровень выраженности шкалы } & \multirow{2}{*}{$\begin{array}{c}\text { Интерпретация } \\
\text { (уровень вы- } \\
\text { раженности } \\
\text { значения) }\end{array}$} \\
\hline & & Мл. командиры & $\begin{array}{c}\text { Подчиненные } \\
\text { курсанты }\end{array}$ & \\
\hline 1. & Авторитарный & 8,4 & 6,4 & $\begin{array}{c}\text { Выше среднего/ } \\
\text { средний }\end{array}$ \\
\hline 2. & Эгоистичный & 6,0 & 5,6 & Средний \\
\hline 3. & Агрессивный & 5,3 & 4,4 & $\begin{array}{l}\text { Средний/ниже } \\
\text { среднего }\end{array}$ \\
\hline 4. & Подозрительный & 2,8 & 2,5 & Низкий \\
\hline 5. & Подчиняемый & 3,4 & 2,7 & Низкий \\
\hline 6. & Зависимый & 4,4 & 3,7 & $\begin{array}{l}\text { Ниже среднего/ } \\
\text { низкий }\end{array}$ \\
\hline 7. & Дружелюбный & 6,0 & 4,5 & $\begin{array}{l}\text { Средний/ниже } \\
\text { среднего }\end{array}$ \\
\hline 8. & Альтруистический & 5,5 & 4,0 & Средний/низкий \\
\hline
\end{tabular}

Результаты исследования показали подавляющее совпадение выраженности шкал по опроснику Т. Лири самооценки командиров и оценки их со стороны подчиненных. Однако наиболее выраженные направленности интерперсональных отношений (авторитарность, дружелюбность и альтруистичность) имеют расхождения в оценках при вышеуказанных условиях. Только эгоистическая направленность младших командиров не вызвала сомнения у подчиненных курсантов.

Можно заметить, что несовпадение имеется по тем направленностям, которые имеют наибольшую выраженность в поведенческом аспекте и обладают большей значимостью для подчиненных курсантов. Данные направленности легче оценить, опираясь на особенности поведенческой сферы командиров младшего звена.

Также из результатов исследования видно, что указанные направленности межличностных отношений были оценены ниже подчиненными курсантами, нежели младшими командирами.

Опираясь на общие представления об образе руководителя, младшие командиры высоко оценивают у себя авторитарную позицию по отношению 
к курсантам своего подразделения. Тем самым обнаруживается желание обладать данным качеством, чтобы удовлетворить интересы вышестоящего руководства. Одновременно младшие командиры полагают, что способны проявлять дружелюбность и альтруистичность по отношению к своим подчиненным. Эти данные могут свидетельствовать о неустойчивой позиции младших командиров в социальной структуре подразделения курса. С одной стороны, подстраиваясь под требования командиров курса, они пытаются занимать авторитарную и независящую позицию по отношению к подчиненным курсантам. С другой стороны, являясь частью курсантского коллектива, младшие командиры стараются проявлять к своим подчиненным доброжелательное отношение.

Также по результатам данного мониторинга можно отметить, что у младших командиров на среднем уровне выражены такие направленности в межличностных отношениях, как эгоистичность и агрессивность. Это может говорить о склонности к соперничеству и самоутверждению, наличии требовательности к окружающим людям, что является показателем недостаточной зрелости и чувства беспомощности у младших командиров как руководителей. В данном случае младшие командиры замещают деятельность по управлению коллективом действиями, направленными на самоутверждение и самолюбование.

В связи с этим, возникает потребность ввести систему подготовки младших командиров, которая будет направлена на формирование готовности к управленческим действиям и умения адекватно выбирать направленность интерперсональных отношений в условиях становления курсантского коллектива.

Далее мы решили посмотреть, какими же качествами должен обладать младший командир, по мнению курсантов и самих младших командиров.

Если сравнить показатели таблиц 1 и 2, то можно предположить, что младшие командиры считают свое поведение по отношению к подчиненным близким к идеалу.

Исходя из полученных данных, наиболее подходящими направленностями интерперсональных отношений младших командиров, по мнению их самих и подчиненных курсантов, являются: агрессивность, эгоистичность, дружелюбность и альтруистичность.

Повышенный уровень авторитарности личности оказывает влияние на социальное поведение личности, актуализируя такие мотивы поведения, как соперничество и конфронтация [17]. В норме такие тенденции способствуют установлению лидирующей позиции младшего командира, помогая ему справляться со своими обязанностями как координатора учебно-служебной деятельности своего подразделения. Стоит отметить, что выраженность 
авторитарной позиции личности в сочетании с общей незрелостью может быть причиной повышенной конфликтности личности и ухудшения психологического климата в коллективе.

Таблича 3.

Особенности интерперсональных отношений «идеального командира младшего звена» по мнению подчиненных курсантов и самих командиров

\begin{tabular}{|c|c|c|c|c|}
\hline \multirow[b]{2}{*}{ № $n / n$} & \multirow{2}{*}{$\begin{array}{c}\text { Виды направленно- } \\
\text { стей межличност- } \\
\text { ных отношений }\end{array}$} & \multicolumn{2}{|c|}{$\begin{array}{c}\text { Уровень выраженности } \\
\text { шкалы }\end{array}$} & \multirow{2}{*}{$\begin{array}{c}\text { Интерпретация } \\
\text { (уровень вы- } \\
\text { раженности } \\
\text { значения) }\end{array}$} \\
\hline & & $\begin{array}{c}\text { Мл. } \\
\text { командиры }\end{array}$ & $\begin{array}{c}\text { Подчиненные } \\
\text { курсанты }\end{array}$ & \\
\hline 1. & Авторитарный & 8,6 & 7,8 & $\begin{array}{l}\text { Выше среднего/ } \\
\text { средний }\end{array}$ \\
\hline 2. & Эгоистичный & 5,4 & 5,1 & Средний \\
\hline 3. & Агрессивный & 4,7 & 4,3 & $\begin{array}{l}\text { Ниже среднего/ } \\
\text { ниже среднего }\end{array}$ \\
\hline 4. & Подозрительный & 2,1 & 1,6 & Низкий \\
\hline 5. & Подчиняемый & 3,0 & 2,7 & Низкий \\
\hline 6. & Зависимый & 3,9 & 3,6 & Низкий/низкий \\
\hline 7. & Дружелюбный & 5,7 & 5,5 & Средний/средний \\
\hline 8. & Альтруистический & 5,7 & 5,0 & Средний/средний \\
\hline
\end{tabular}

С таких же позиций можно рассмотреть эгоистическую направленность межличностных отношений младших командиров. С одной стороны, эгоистическая направленность имеет отрицательную окраску, как направленность на удовлетворение своих потребностей. В то время как потребности и желания других индивидов не имеют определяющего значения. С другой стороны, в умеренной выраженности в структуре мотивационной направленности командиров младшего звена учебных заведений экстремального профиля она может способствовать достижению целей коллектива. Амбивалентная сущность эгоизма, например, продемонстрирована в одной из работ Э. Фромма: «Современная культура вся пронизана табу на эгоизм. Нас научили тому, что быть эгоистичным грешно, а любить других добродетельно. 
Несомненно, это учение находится в вопиющем противоречии с практикой современного общества, признающего, что самое сильное и законное стремление человека - это эгоизм...» $[19$, с. 560]. Если «базовый эгоизм» способствует немедленному удовлетворению собственных потребностей, то «разумный эгоизм» в большей степени может быть основан на стремлении к сотрудничеству и удовлетворению потребностей подчиненного коллектива как показатель успешности деятельности руководителя [12].

Помимо агрессивной и эгоистической направленности межличностных отношений «идеальных» младших командиров, выделяются и такие, казалось бы, положительные направленности, как дружелюбная и альтруистическая. Однако при ближайшем рассмотрении они также имеют свое амбивалентное значение.

Проявление альтруизма может быть связано с наличием мотивов морального долга и морального сочувствия. В этом случае поступки, направленные на объект помощи, могут носить характер нравственного удовлетворения и не являться истинным показателем положительного отношения к другому человеку. Данное проявление альтруизма носит отрицательный характер, близкий по содержанию с эгоистической мотивацией. Во втором случае альтруизм проявляется в связи с идентификацией, отождествлением с другим человеком, сопереживанием, но никогда не заканчивается действием [9].

Альтруистическая направленность младших командиров, как способность проявлять внимание и доброжелательность к подчиненным, положительно сказывается на психологической атмосфере подразделения. Кроме того, наличие альтруистической направленности командиров способствует их сближению с подчиненными, увеличивая число союзников среди курсантов в собственном подразделении. Курсанты с большим желанием будут делиться с таким командиром о происходящих событиях внутри учебной группы [13].

Выраженная дружелюбная направленность младшего командира будет положительно влиять на взаимоотношения с одногруппниками, но отрицательно - на общую результативность подразделения.

Таким образом, опросник Т. Лири может быть использован для диагностики доминирующей направленности межличностных отношений командиров младшего звена с целью определения индивидуального направления работы с ними в период становления. Прикладным результатом нашего исследования является: составление диагностического инструментария, позволяющего определить наиболее подходящих кандидатов на должности младших командиров; составление рекомендаций для командования курса по поддержке начинающих командиров с учетом их индивидуальных особенностей. 
Теперь обратимся к результатам корреляционного анализа (таблица 4).

Зависимость направленности межличностных отношений командиров младшего звена от их мотивационной сферы

\begin{tabular}{|c|c|c|c|c|c|c|c|c|}
\hline & \multicolumn{8}{|c|}{ Направленность межличностных отношений } \\
\hline & 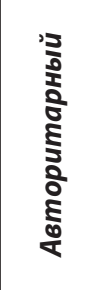 & 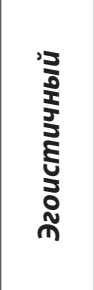 & 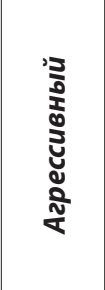 & 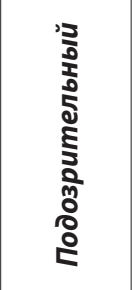 & 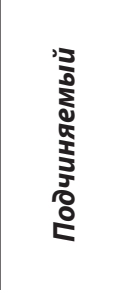 & 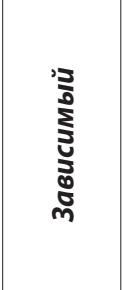 & 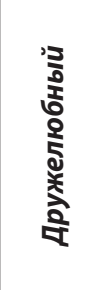 & 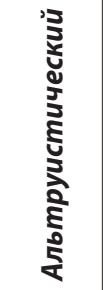 \\
\hline Мак-шкала & $-0,026$ & 0,136 & 0,155 & $0,379 * *$ & 0,049 & 0,041 & 0,048 & $-0,107$ \\
\hline $\begin{array}{c}\text { Мотивация } \\
\text { достижения }\end{array}$ & $0,301 *$ & 0,010 & $-0,075$ & $-0,374 * *$ & $-0,369 * *$ & $-0,360 * *$ & $-0,112$ & 0,045 \\
\hline $\begin{array}{c}\text { Направленность } \\
\text { на себя }\end{array}$ & $-0,132$ & 0,006 & $0,325 *$ & $0,395^{*}$ & 0,047 & $-0,027$ & 0,023 & $-0,183$ \\
\hline $\begin{array}{c}\text { Направленность } \\
\text { на взаимодей- } \\
\text { ствие }\end{array}$ & 0,138 & $-0,038$ & $-0,086$ & $-0,453 * *$ & $-0,014$ & $-0,039$ & $-0,071$ & 0,130 \\
\hline $\begin{array}{c}\text { Направленность } \\
\text { на задачу }\end{array}$ & 0,022 & 0,038 & $-0,174$ & 0,036 & $-0,079$ & 0,033 & 0,016 & 0,055 \\
\hline
\end{tabular}

**. Коррелячия значима на уровне 0,01 (двухсторонняя).

*. Коррелячия значима на уровне 0,05 (двухсторонняя).

Результаты корреляционного анализа показали интересную закономерность: мотивационная сфера младших командиров тесно связана с такой направленностью интерперсональных отношений, как подозрительность.

Если рассматривать подозрительность как черту характера, то она соотносится с неуверенностью в себе, низкой самооценкой и повышенной критичностью по отношению к окружающим. Главным образом, она связана с направленностью младшего командира на себя $(r=0,395$, при $p \leq 0,01)$. У такой личности преобладает мотив собственного благополучия, стремления к собственному первенству и превосходству в ущерб потребностям окружающих [15]. Такой командир будет выгоден командованию курса, 


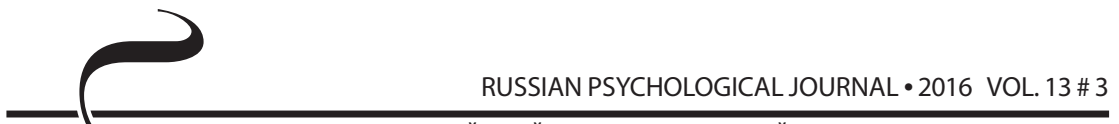

РОССИЙСКИЙ ПСИХОЛОГИЧЕСКИЙ ЖУРНАЛ • 2016 ТОМ 13 № 3

т. к. будет стараться выполнять все их поручения, чтобы закрепить свою формальную позицию «над» другими курсантами. Однако данное качество будет препятствовать его активному становлению как младшего командира, блокируя его личностный потенциал. Главной мотивацией такого младшего командира будет избегание неудачи ( $r=0,395$, при $p \leq 0,01)$. Его деятельность будет подчиняться потребности нахождения в «зоне комфорта».

Предсказуемо, что подозрительность в интерперсональных отношениях будет препятствовать продуктивным взаимоотношениям между младшим командиром и подчиненными курсантами $(r=-0,453$, при $p \leq 0,05)$. Также здесь имеет смысл обратить внимание на то, что в данном случае неумение наладить продуктивные взаимоотношения будут компенсироваться манипулятивными тенденциями в отношениях с людьми ( $r=0,379$, при $p \leq 0,05)$. Младшему командиру с направленностью на подозрительность в межличностных отношениях легче воспользоваться техникой манипулирования, которая является менее энергозатратной, чем прикладывать усилия для достижения авторитета. Как отмечает С. А. Зелинский, манипулирование связано с общей теорией выживаемости видов и связано с подавлением одними других, установлением показной власти и величия [6].

Рассмотрим, с какими направленностями в межличностных отношениях командиров младшего звена связана мотивация достижения. Наличие данной мотивации в мотивационной структуре командира младшего звена имеет принципиальное значение. Она может свидетельствовать о стремлении к достижению высоких результатов в деятельности, по средствам совершенствования своих профессиональных навыков и умений, а также личностного развития [18]. Обращаясь к вышеизложенным результатам нашего исследования, в среднем у младших командиров отмечается стремление избегать неудачи. То есть, необходимо проводить дополнительную диагностику претендентов на должности младших командиров, которая позволяла бы выявлять возможные «слабые» и «сильные» стороны претендентов. Полученные данные можно будет использовать в качестве основы для разработки индивидуальных рекомендаций по дальнейшему развитию «сильных» сторон командира и по минимизации - «слабых».

Мотивация достижения напрямую связана с наличием авторитарной направленности в межличностных отношениях командиров младшего звена $(r=0,301$, при $p \leq 0,05)$. Уровень выраженности авторитарной направленности у младших командиров, как мы уже отмечали, -выше среднего. Авторитарная направленность является желательной в структуре интерперсональных отношений младших командиров.

Отрицательное влияние на стремление младшего командира к высокому результату в деятельности оказывает наличие следующих направленностей 
в межличностных отношениях: подозрительность ( $r=-0,374$, при $p \leq 0,01)$, подчиняемость $(r=-0,369$, при $p \leq 0,01)$, зависимость $(r=-0,360$, при $p \leq 0,01)$.

\section{Заключение}

Подведем итоги проведенного исследования:

1. Мотивационная сфера младших командиров оказывает непосредственное влияние на процесс построения межличностных отношений с подчиненными курсантами в процессе учебно-служебной деятельности.

2. Особенности интерперсональных отношений влияют на продуктивность деятельности подразделения.

3. Необходимо ввести алгоритм социально-психологического отбора младших командиров, который учитывал бы тенденции интерперсональных отношений претендентов на сержантские должности в учебных заведениях МЧС России.

4. Важной является разработка рекомендаций для командиров младшего звена по развитию управленческого потенциала на основе построения межличностных отношений с подчиненными курсантами.

\section{Литература}

1. Ахвердова О. А., Волоскова Н. Н., Белых Т. В. Дифференциальная психология: теоретические и прикладные аспекты исследования интегральной индивидуальности. Учеб. пособие. -СПб.: Речь, 2004. - 168 с.

2. Гулиев М. А., Епифанцев С. Н., Самыгин С. И. Социология и психология управления. - Ростов н/Д: Феникс, 2006. - 409 с.

3. Доценко Е. Л. Психология манипуляции. Феномены, механизмы, защита. - М.: Изд-во МГУ, 1996. - 480 с.

4. Журавлев П. В., Карташов С. А., Маусов Н. К., Одегов Ю. Г. Технология управления персоналом. Настольная книга менеджера. -М.: Экзамен, 1999. - 576 с.

5. Зелинский С. А. Манипулирование личностью и массами. Манипулятивные технологии власти при атаке на подсознание индивида и масс. СПб.: Издательско-Торговый Дом «СКИФИЯ», 2008. - 240 с.

6. Знаков В. В. Макиавеллизм: психологическое свойство личности и методика его исследования // Психологический журнал. - 2000. - № 5.

7. Знаков В. В. Психология понимания: проблемы и перспективы. -М., 2005.

8. Ильин Е. П. Мотивация и мотивы. -СПб.: Питер, 2006. - 512 с.

9. Ильин Е. П. Эмоции и чувства. -СПб.: Питер, 2001. - 752 с.

10. Калюжный А. С. Психология межличностного общения: Учеб. пос. Н. Новгород: Изд-во НГТУ, 2004. - 32 с.

11. Королев С. О., Жулина М. В. Влияние личностных особенностей на эффективность деятельности младших командиров // Сб. научно-методических 
материалов научно-практической конференции «Актуальные проблемы вузовского военного образования, гуманитарных и социально-политических наук». - Вып. 30. - Ч. 4. - Воронеж: Изд-во ВВВАИУ, 2007. -С. 74-77.

12. Левит Л. 3. Счастье, эгоизм, альтруизм: парадоксы взаимодействия // Научно-практический журнал «Психология. Социология. Педагогика». 2012. - № 7. - С. 10-19.

13. Мигунова Ю. С. Исследование взаимоотношений между курсантами института МЧС и командирами младшего звена // Ученые записки: электронный научный журнал Курского государственного университета. - 2014. - № 4 (32). - URL: http://www.scientific-notes.ru/pdf/037-037.pdf

14. Организация и проведение профессионального психологического отбора в военно-учебных заведениях МО РФ: метод. рекомендации / Под общ. ред. А. Г. Маклакова и др. - М: Воениздат, 2002. - 287 с.

15. Розов А. И. Стремление к превосходству как одно из основных влечений // Психологический журнал. - 1993. - № 6. - С. 134.

16. Собчик Л. Н. Методы психологической диагностики. Вып. 3. Диагностика межличностных отношений. Модифицированный вариант интерперсональной диагностики Т. Лири. Метод. руководство. - М., 1990.

17. Фетискин Н. П., Козлов В. В., Мануйлов Г. М. Социально-психологическая диагностика развития личности и малых групп. - М.: Изд-во Института психотерапии, 2002.

18. Фомишин А. М. Стили поведения и показатели агрессивности в межличностных взаимоотношениях курсантов высших военных учебных заведений // Известия Российского государственного педагогического университета им. А. И. Герцена. - 2008. - № 63-2.

19. Фромм Э. Человек для самого себя. - М.: АСТ, 2008. - 700 с.

20. Ames M., Kidd A. H. Machiavellianism and women's grade point averages // Psychological Reports. - 1979. -V. 44. - no. 1. - pp. 223-228.

\section{References}

1. Akhverdova O. A., Voloskova N. N., Belykh T. V. Differentsial'naia psikhologiia: teoreticheskie i prikladnye aspekty issledovaniia integral'noi individual'nosti [Differential psychology: theoretical and applied aspects of the study of integral individuality]. St. Petersburg, Rech' Publ., 2004. 168 p.

2. Guliev M. A., Epifantsev S. N., Samygin S. I. Sotsiologiia i psikhologiia upravleniia [The sociology and psychology of management]. Rostov-onDon, Feniks, 2006. 409 p.

3. Dotsenko E. L. Psikhologiia manipuliatsii. Fenomeny, mekhanizmy, zashchita [The psychology of manipulation: the phenomena, mechanisms, and protection]. Moscow, MSU Publ., 1996. 480 p. 
4. Zhuravlev P. V., Kartashov S. A., Mausov N. K., Odegov lu. G. Tekhnologiia upravleniia personalom [Techniques of personnel management]. Moscow, Ekzamen Publ., 1999. 576 p.

5. Zelinskii S. A. Manipulirovanie lichnost'iu i massami. Manipuliativnye tekhnologii vlasti pri atake na podsoznanie individa i mass [Manipulation of individuals and the masses. Manipulative techniques of power in attacking the subconsciousness of individuals and the masses]. St. Petersburg, SKIFlla Publ., 2008. 240 p.

6. Znakov V.V. Makiavellizm: psikhologicheskoe svoistvo lichnosti i metodika ego issledovaniia [Machiavellianism: personal psychological attribute and the technique of its research]. Psikhologicheskii zhurnal - Psychological Journal, 2000, no. 5.

7. Znakov V.V.Psikhologiia ponimaniia: problemy i perspektivy [The psychology of understanding: problems and prospects]. Moscow, 2005.

8. Il'in E. P. Motivatsiia i motivy [Motivation and motives]. St. Petersburg, Piter Publ., 2006. 512 p.

9. Il'in E. P. Emotsii i chuvstva [Emotions and feelings]. St. Petersburg, Piter Publ., 2001. 752 p.

10. Kaliuzhnyi A. S. Psikhologiia mezhlichnostnogo obshcheniia [The psychology of interpersonal communication]. N. Novgorod, Nizhny Novgorod State Technical University Publ., 2004. 32 p.

11. Korolev S. O., Zhulina M. V. Vliianie lichnostnykh osobennostei na effektivnost' deiatel'nosti mladshikh komandirov [The influence of personal traits on the effectiveness of junior commanders]. Sb. nauchno-metodicheskikh materialov nauchno-prakticheskoi konferentsii «Aktual'nye problemy vuzovskogo voennogo obrazovaniia, gumanitarnykh i sotsial'no-politicheskikh nauk» [Proc. Theoretical and Practical Conference "Urgent problems of higher military education, humanities, and socio-political sciences"]. Voronezh, Voronezh Military Institute of Aviation and Engineering Publ., 2007, V. 30, Part 4, pp. 74-77.

12. Levit L. Z. Schast'e, egoizm, al'truizm: paradoksy vzaimodeistviia [Happiness, egoism, and altruism: paradoxes of interaction]. Nauchno-prakticheskii zhurnal «Psikhologiia. Sotsiologiia. Pedagogika» - "Psychology. Sociology. Pedagogy" Theoretical and Practical Journal, 2012, no. 7, pp. 10-19.

13. Migunova lu. S. The study of the relationship between cadets of the Institute of Emergency Situations Ministry and junior commanders. Available at: http://www.scientific-notes.ru/pdf/037-037.pdf

14. Maklakov A. G. Organizatsiia i provedenie professional'nogo psikhologicheskogo otbora $v$ voenno-uchebnykh zavedeniiakh MO RF [The organization and realization of professional psychological selection in military educational institutions of the Ministry of Defence of the Russian Federation]. Moscow, Voenizdat Publ., 2002. 287 p. 
РОССИЙСКИЙ ПСИХОЛОГИЧЕСКИЙ ЖУРНАЛ • 2016 ТОМ 13 № 3

15. Rozov A. I. Stremlenie k prevoskhodstvu kak odno iz osnovnykh vlechenii [Striving for superiority as one of the main drives]. Psikhologicheskii zhurnal - Psychological Journal, 1993, no. 6, P. 134.

16. Sobchik L. N. Metody psikhologicheskoi diagnostiki. Vyp. 3. Diagnostika mezhlichnostnykh otnoshenii. Modifitsirovannyi variant interpersonal'noi diagnostiki T. Liri [Methods of psychological diagnostics. V. 3. Diagnostics of interpersonal relations. A modified version of Leary interpersonal diagnosis]. Moscow, 1990.

17. Fetiskin N. P., Kozlov V. V., Manuilov G. M. Sotsial'no-psikhologicheskaia diagnostika razvitiia lichnosti i malykh grupp [Socio-psychological diagnostics of the development of personality and small groups]. Moscow, Institute of Psychotherapy Publ., 2002.

18. Fomishin A. M. Stili povedeniia i pokazateli agressivnosti v mezhlichnostnykh vzaimootnosheniiakh kursantov vysshikh voennykh uchebnykh zavedenii [Styles of behavior and indicators of aggressiveness in interpersonal relations in cadets of the higher military educational institutions]. Izvestiia Rossiiskogo gosudarstvennogo pedagogicheskogo universiteta im. A. I. Gertsena-Proceedings of Russian State Pedagogical University named A. I. Herzen, 2008, no. 63-2.

19. Fromm E. A Man for Himself(Russ. ed.: Fromm E. Chelovek dlia samogo sebia. Moscow, AST Publ., 2008. 700 p.).

20. Ames M., Kidd A. H. Machiavellianism and women's grade point averages. Psychological Reports, 1979, V. 44, no. 1, pp. 223-228. 